\title{
Service Fairness Scale: Development, Validation, and Structure
}

\author{
Shueh-Chin Ting ${ }^{1}$ \\ ${ }^{1}$ Program of Educational Entrepreneurship and Management, Department of Education, National University of \\ Tainan, Taiwan \\ Correspondence: Shueh-Chin Ting, Program of Educational Entrepreneurship and Management, Department of \\ Education, National University of Tainan, 33 Section 2, Shu-Lin Street, Tainan 70005, Taiwan. E-mail: \\ tingsc@ms49.hinet.net
}

Received: August 6, 2013

Accepted: September 5, 2013

Online Published: November 7, 2013

doi:10.5539/ijms.v5n6p25

URL: http://dx.doi.org/10.5539/ijms.v5n6p25

\begin{abstract}
Service fairness lacks a clear dimensionality and there remains uncertainty about the structural relationship among dimensions within this construct. A comprehensive measurement model of service fairness in the context of consumer-retailer is developed in this study. We make a theoretical justification of the five dimensions which composes this construct and its factor structure. According to the systematic approach, we obtain five reliable and valid subscales of service fairness and also confirm service fairness is a three-order structural model.
\end{abstract}

Keywords: factor structure, measurement, scale, service fairness

\section{Introduction}

Following the principles of relationship marketing, many service providers treat customers differently based on their profitability (Mayser \& von Wangenheim, 2013). It produces many fairness problems. Although the concept of fairness has received great attention in consumer behavior research lately (Nguyen \& Klaus, 2013), extant research on fairness adopts many dimensions whose definitions and measures vary (Blader \& Tyler, 2003). Thus, these fairness studies lack comparability (Darke \& Dahl, 2003; Clemmer, 1993).

Dimensionality of service fairness lacks a consensus opinion (Ashworth \& Free, 2006). Its dimensionality maybe a single underlying dimension (e.g., Cropanzano \& Ambrose, 2001; Lind, 2001), two dimensions (i.e., distributive \& procedural fairness) (e.g., Brockner \& Wiesenfeld, 1996) or more other dimensions including interactional (e.g., Bies \& Moag, 1986; Colquitt, 2001; Cropanzano, Byre, Bobocel, \& Rupp, 2001), interpersonal (e.g., Carr, 2007; Colquitt, Wesson, Porter, Conlon, \& Ng, 2001) and informational fairness (e.g., Carr, 2007; Colquitt, Wesson, Porter, Conlon, \& Ng, 2001). In near years, relatively complete research on service fairness is Carr (2007). Five distinct fairness of distributive, procedural, interpersonal, informational, and systemic or overall fairness were discussed in the article. However, the work focused on the first four fairness influences systemic or overall fairness. It was not a rigorous scale development research and did not involve the factor structure of service fairness.

Considering all that exposed, and in the absence of a clear and complete dimensionality and factor structure of service fairness, the present study widely collects the items of service fairness and develops a thorough tool to measure service fairness. The main contributions of this article have three aspects. First, this article provides a reliable and valid scale of measurement for this construct, especially applicable to the context of consumer-retailer. Second, this article identifies the dimensionality of service fairness. Third, this article develops a higher order factor model.

\section{Multidimensional Structure of Service Fairness}

The literature discusses various dimensions of fairness however these lack systematic integration. In the following paragraphs we review the fairness literature on the development of fairness dimensions.

\subsection{Distributive Fairness}

Both equity theory and the theory of distributive justice argue that individuals general use the concept of equity to evaluate the distribution of outcomes (Cohen, 1987). Equity assessment involves individuals comparing inputs and outcomes relative to a reference point (Gilliland, 1993; Lacey \& Sneath, 2006; Xia, Monroe, \& Cox, 2004). So, consumers perceive distributive fairness when they perceive outcomes as commensurate with their inputs 
(Homans, 1961; Sindhav, Holland, Rodie, Adidam, \& Pol, 2006). Distributive fairness in the context of service delivery involves the four principles of cost, amount of service, correctness, and excellence (Bowen, Gilliland, \& Folger, 1999). Cost represent a consumer's input; on the other hand, the amount of service, correctness, and excellence are outcomes. Based on the concept of distributive fairness we divide distributive fairness into outcome fairness and input (price) fairness.

\subsubsection{Outcome Fairness}

Outcome fairness is a customer's assessment about whether s/he receives the service outcome, either in terms of quantity or quality, equivalent to that other customers receive.

\subsubsection{Price Fairness}

Price fairness considers the buyer's assessment about the difference, or lack of, between a seller's price and that of other comparative sellers is reasonable, acceptable or justifiable. A customer perceives price unfairness when s/he pays a higher price than other customers but receives a same quality product (Martins \& Monroe, 1994). In addition, the gap between the expected and the actual price leads the customer to feel $\mathrm{s} / \mathrm{he}$ has been treated unfairly (Yieh, Chiao, \& Chiu, 2007).

\subsection{Procedural Fairness}

Organizational procedures represent the activities and policies the organization uses to allocate resources (Carr, 2007). In exercising these procedures Leventhal's (1980) identifies rules to create procedural fairness that include: consistency, neutrality, accuracy of information and freedom from bias. Customers consider a service procedural fair through adherence to these rules. Under the situation which service procedure is fair, all customers receive the same service procedures. There is no bias in the application of service procedures (Carr, 2007).

\subsection{Interactional Fairness}

An organization interacts with customers through its representatives. Some fairness problems are related with representatives of the organization. Interactional fairness concerns individuals' actions and behaviors occurring during procedures of service delivery (Sindhav, Holland, Rodie, Adidam, \& Pol, 2006) and focuses on human interaction and communication process between the source and the recipient of fairness (Bies \& Moag, 1986; Tyler \& Bies, 1990). Specifically, interactional fairness is judged by: (1) justification: providing explanations so participants understand the rationale behind decisions, (2) truthfulness: candidness, (3) respect: behaving politely, and (4) propriety: behaving appropriately (Bies \& Moag, 1986). Interactional fairness considers the fairness associated with the exchange of information and communication for outcomes (Goodwin \& Ross, 1992). Greenberg (1993) and Colquitt (2001) present a two-dimensional conceptualization of interactional fairness as interpersonal and informational fairness.

\subsubsection{Interpersonal Fairness}

Interpersonal fairness concerns the manner in which outcomes are distributed. This may be as simple as smiling and greeting customers but can involve a concerted effort to give all customers polite and personal attention (Carr, 2007; Greenberg, 1993). Interpersonal treatment associates with interactional fairness to explain the two-way flows between consumers and service providers. This includes the manner in which the customer is treated in terms of respect, interest, friendliness, honesty, and politeness (Lacey \& Sneath, 2006).

\subsubsection{Informational Fairness}

Customers evaluate how processes are implemented and the way in which the processes and outcomes are explained (Lacey \& Sneath, 2006). Informational fairness is defined as providing information or knowledge to consumers to explain outcomes and procedures (Goodwin \& Ross, 1992; Greenberg, 1993). Consequently, it involves consumers' perception about open, thorough, reasonable, and timely communication from the service personnel (Sindhav, Holland, Rodie, Adidam, \& Pol, 2006). Consumers' perceptions of service fairness are not only based on perceived service differences, but also information. It helps buyers to judge whether the seller should be responsible for the service difference and whether such difference is reasonable. Marketers can provide relevant information to influence buyers' attributions for the service discrepancies. This may be as basic as providing brochures or as intricate as providing long, multifaceted explanations of complex services (Carr, 2007).

\subsection{Overall Fairness}

Several researchers posit the existence of an overall fairness that emerges from perceptions of distributive, procedural, and interactional fairness (Beugre, 1998; Carr, 2007; Greenberg, 1996). While the literature suggests 
the concept of overall fairness it has not been empirically validated, nor has its role in more elaborated theory been established (Carr, 2007). In this study address this gap in our understanding by empirically testing for an overall fairness construct and examining its relationship with other fairness dimensions.

\section{Research Design}

To extend previous research on service fairness and to develop the service fairness scale, we employed both qualitative and quantitative methods, and followed Churchill's (1979) and Gerbing and Anderson's (1988) paradigm for development of marketing scales.

First, to develop the measured items, we used some qualitative methods such as depth interview and focus group interview. Then, we used the quantitative method to identify the different dimensions of service fairness, construct their corresponding scales and test the relationship among the dimensions.

Respondents were auto repair customers in Taiwan. Auto repair centers offer the customers a wide variety of services to meet differing requirements demanded by very varied segments. On the other hand, the services they offer have many fairness problems. Therefore, auto repair centers are suitable to fairness research. Through personal contacts we identified an auto repair center that gave us permission to collect data. At the auto repair center we gave questionnaires to customers who had just finished auto repair (i.e., a convenience sampling strategy). The questionnaires were collected in the same manner at each of the four stages of scale development. In the first two stages of scale purification we separately collected 80 valid questionnaires. In the third stage of testing the scales dimensionality, reliability and validity we collected 200 valid questionnaires. Finally, in the fourth stage we collected 178 questionnaires to confirm the stability of our proposed service fairness scales.

\section{Constructing Consumers' Service Fairness Scale}

\subsection{Step 1 Understanding the Definition of Service Fairness}

As suggested by Churchill (1979) the first step involved was specifying the domain of the construct to delineate exactly what is included in the definition. Unlike service quality which is evaluated through a comparison with some personal expectations of favorableness, service fairness has a different comparison base. The comparison base is that how similar others were actually treated by the service providers. Our literature review reveals there are five types of service fairness i.e., outcome, price, procedural, interpersonal, and informational fairness. Outcome fairness relates to the core services which consumers acquire. Price fairness concerns the cost consumers pay. Procedural fairness relates to the process by which consumers acquire services. Interpersonal fairness addresses the personal interaction between consumers and service providers. Informational fairness relates to the information that service providers provide to consumers.

Table 1. Items of service fairness scale

\begin{tabular}{|c|c|c|c|}
\hline Construct / dimension & Code & Items & Source \\
\hline \multicolumn{4}{|l|}{ DISTRIBUTIVE } \\
\hline \multirow{9}{*}{$\begin{array}{l}\text { FAIRNESS } \\
\text { Outcome fairness }\end{array}$} & & & \\
\hline & OUT1 & $\begin{array}{l}\text { Service staff help all customers get the outcomes they need } \\
\text { without favoring any one group }\end{array}$ & Carr (2007) \\
\hline & OUT2 & $\begin{array}{l}\text { Service staff produce desired results for all customers } \\
\text { without bias of any kind }\end{array}$ & Carr (2007) \\
\hline & OUT3 & $\begin{array}{l}\text { Service staff deliver good outcomes for all customers } \\
\text { regardless of who they are }\end{array}$ & Carr (2007) \\
\hline & OUT4 & $\begin{array}{l}\text { In general, service staff deliver reasonable results for all } \\
\text { customer }\end{array}$ & Carr (2007) \\
\hline & OUT5 & I can get the same outcomes as others do & Sindhav et al. (2006) \\
\hline & OUT6 & $\begin{array}{l}\text { Service staff provide me service amount same as I expected } \\
\text { (deleted) }\end{array}$ & Bowen et al. (1999) \\
\hline & OUT7 & $\begin{array}{l}\text { Service staff deliver the promised service accurately the } \\
\text { first time (deleted) }\end{array}$ & Bowen et al. (1999) \\
\hline & OUT8 & $\begin{array}{l}\text { Service staff provide me service quality same as I expected } \\
\text { (deleted) }\end{array}$ & Bowen et al. (1999) \\
\hline \multirow[t]{3}{*}{ Price fairness } & PRI1 & Labor wages charged by the service center are reasonable & $\begin{array}{l}\text { Bei \& Chiao (2001); Yieh, Chiao, } \\
\text { \& Chiu (2007) }\end{array}$ \\
\hline & PRI2 & $\begin{array}{l}\text { Cost of auto parts charged by the service center is } \\
\text { reasonable }\end{array}$ & $\begin{array}{l}\text { Bei \& Chiao (2001); Yieh, Chiao, } \\
\& \text { Chiu (2007) }\end{array}$ \\
\hline & PRI3 & Labor wages charged by the service center are acceptable & New \\
\hline
\end{tabular}




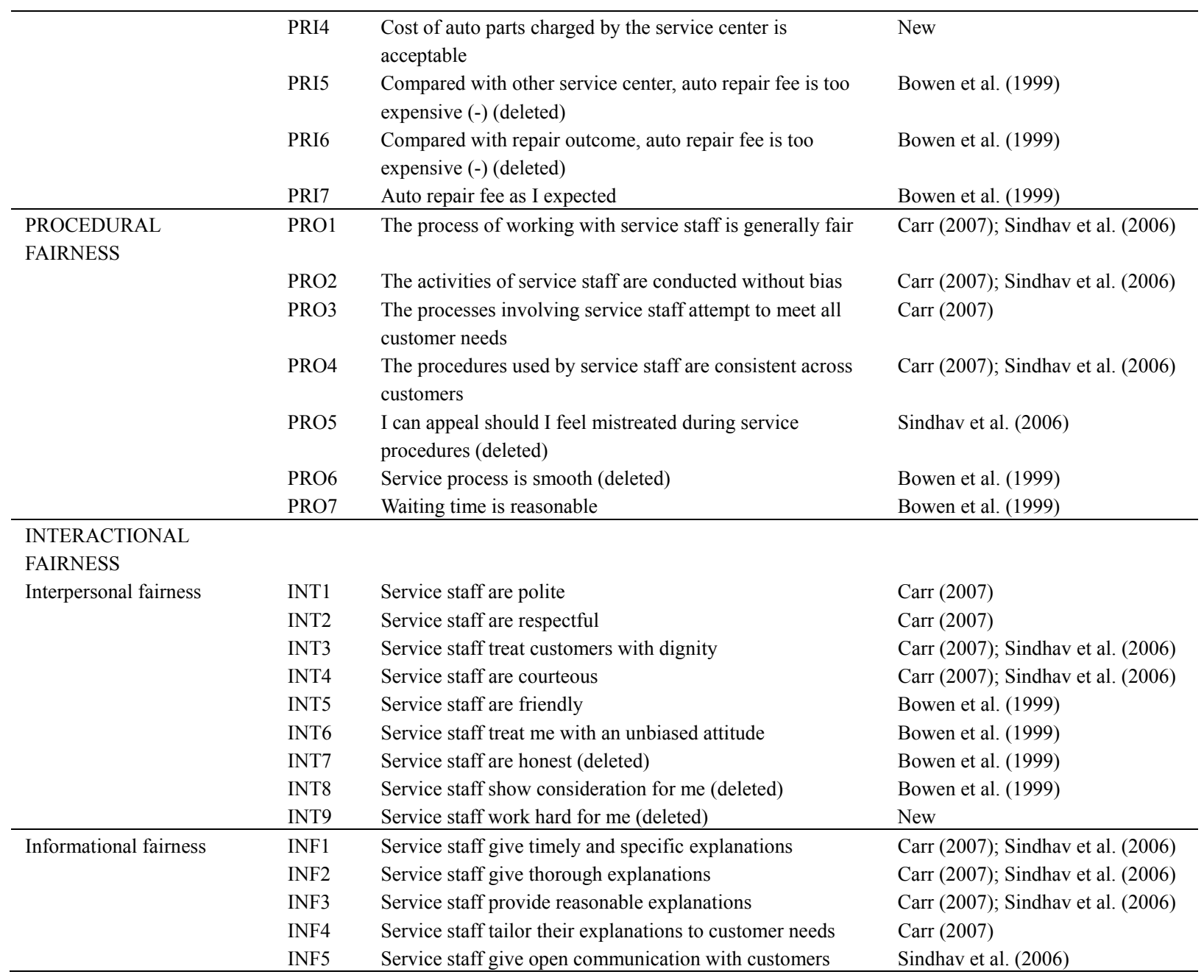

\subsection{Step 2 Generation of Scale Items}

After defining all dimensions specifically, we developed initial items through reviewing extant literature and summarizing opinions of a few consumers and professors. We interviewed ten consumers of auto repair service through the method of critical incident technique and five professors teaching service management as a focus group. Thirty six initial items were collected. Through comparing our thirty six items with literature, our analysis found three additional items. We showed the details in Table 1. Each item in the measure was formed on a 7 -point Likert Scale ranging from "very strongly disagree" to "very strongly agree".

\subsection{Step 3 Scale Item Purification-First Stage}

We conducted two exploratory factor analyses (EFA) in the purification process of two stages to determine the dimensions of service fairness, and then, followed by two confirmatory factor analyses (CFA) to test the model fit and factor structure.

In the first stage of scale item purification, the first EFA with varimax rotation was applied over the 36 initial items. The result generated seven factors with eigenvalues greater than 1 . We deleted the items with factor loading of below .5 and those with the cross-loadings difference of below .3. Consequently, 10 items were deleted: OUT 6, 7 and 8; PRI 5 and 6; PRO 5 and 6 and INT 7, 8 and 9. This left 26 items and five factors. 
Table 2. Factor loadings for second stage purification

\begin{tabular}{|c|c|c|c|c|c|}
\hline & \multicolumn{4}{|c|}{ Factor } & \multirow[b]{2}{*}{5} \\
\hline & 1 & 2 & 3 & 4 & \\
\hline INT2 & .875 & -.085 & .187 & .139 & .178 \\
\hline INT5 & .852 & .070 & .307 & .154 & .138 \\
\hline INT1 & .829 & -.024 & .297 & .238 & .191 \\
\hline INT3 & .816 & -.016 & .296 & .214 & .103 \\
\hline INT4 & .694 & .164 & .389 & .288 & .137 \\
\hline INT6 & 649 & .205 & .255 & .168 & .293 \\
\hline PRI1 & .016 & .867 & .065 & .207 & .135 \\
\hline PRI2 & -.039 & .853 & .128 & .259 & .145 \\
\hline PRI3 & .247 & .819 & .050 & .118 & .248 \\
\hline PRI4 & .087 & .789 & -.023 & .206 & .332 \\
\hline PRI7 & -.091 & .713 & .019 & .099 & .178 \\
\hline INF3 & .283 & .023 & .853 & .127 & .024 \\
\hline INF2 & .300 & -.031 & .825 & .224 & .187 \\
\hline INF5 & .233 & .307 & .738 & -.005 & .166 \\
\hline INF1 & .289 & -.054 & .723 & .305 & .121 \\
\hline INF4 & .343 & .066 & .715 & .057 & .292 \\
\hline OUT4 & .220 & .169 & .184 & .789 & .122 \\
\hline OUT5 & .093 & .153 & .149 & .721 & .284 \\
\hline OUT3 & .135 & .230 & .086 & .708 & .313 \\
\hline OUT2 & .382 & .250 & .071 & .704 & .211 \\
\hline OUT1 & .219 & .195 & .147 & .639 & .114 \\
\hline PRO4 & .248 & .243 & .133 & .217 & .755 \\
\hline PRO7 & .098 & .258 & .108 & .167 & .724 \\
\hline PRO2 & .293 & .249 & .120 & .365 & .706 \\
\hline PRO1 & .143 & .312 & .316 & .284 & .706 \\
\hline PRO3 & .298 & .309 & .263 & .226 & .623 \\
\hline
\end{tabular}

\subsection{Step 4 Scale Item Purification-Second Stage}

We repeated the process given in step 3. We made the second purification for the 26 items by using another sample $(\mathrm{N}=80)$. The EFA results (Table 2) indicated that these items have strong factor loadings (above .6) and loaded on the expected factors. Up to now, the purpose of purification had attained. Therefore, we continued to the next step of identification of scale dimensions and items.

\subsection{Step 5 Identification of Scale Dimensions and Items}

The results of the EFA revealed five dimensions which are consistent with our initial theoretical classification. The final number of items was distributed as follows: five items for outcome fairness; five items for price fairness; five items for procedural fairness; six items for interpersonal fairness; five items for informational fairness. All items used appear in the Table 1 together with their conceptual source.

\subsection{Step 6 Confirmation of the Scale's Reliability and Validity}

Regarding the identified five dimensions of service fairness, we examined the reliability and validity of the five subscales, including individual item reliability, composite reliability, criterion validity, convergent validity, and discriminant validity. 
Table 3. CFA of the five dimensions of service fairness

\begin{tabular}{|c|c|c|c|c|c|c|c|c|c|c|c|c|c|c|}
\hline Dimension & code & $\mathrm{FL}$ & ER & IR & $\mathrm{CR}$ & $x^{2}(d f)$ & $\mathrm{p}$ & $\mathrm{x}^{2} / \mathrm{df}$ & RMR & GFI & AGFI & CFI & RMSEA & AVE \\
\hline \multirow[t]{5}{*}{ Outcome } & OUT1 & $.83 *$ & .31 & .69 & .90 & $8.67(5)$ & .12 & 1.73 & .016 & .98 & .95 & .99 & .057 & .70 \\
\hline & OUT2 & $.80^{*}$ & .36 & .64 & & & & & & & & & & \\
\hline & OUT3 & $.79 *$ & .37 & .62 & & & & & & & & & & \\
\hline & OUT4 & $.78^{*}$ & .39 & .61 & & & & & & & & & & \\
\hline & OUT5 & $.79 *$ & .37 & .62 & & & & & & & & & & \\
\hline \multirow[t]{5}{*}{ Price } & PRI1 & $.82 *$ & .33 & .67 & .90 & $10.85(5)$ & .054 & 2.17 & .033 & .98 & .94 & .99 & .070 & .62 \\
\hline & PRI2 & $.72 *$ & .48 & .52 & & & & & & & & & & \\
\hline & PRI3 & $.83^{*}$ & .32 & .69 & & & & & & & & & & \\
\hline & PRI4 & $.79 *$ & .38 & .62 & & & & & & & & & & \\
\hline & PRI7 & $.78^{*}$ & .39 & .61 & & & & & & & & & & \\
\hline \multirow[t]{5}{*}{ Procedural } & PRO1 & $.72 *$ & .48 & .52 & .87 & $8.86(5)$ & .11 & 1.77 & .024 & .98 & .94 & .99 & .066 & .56 \\
\hline & $\mathrm{PRO} 2$ & $.72 *$ & .48 & .52 & & & & & & & & & & \\
\hline & PRO3 & $.79^{*}$ & .38 & .62 & & & & & & & & & & \\
\hline & PRO4 & $.78^{*}$ & .40 & .61 & & & & & & & & & & \\
\hline & PRO7 & $.74 *$ & .45 & .55 & & & & & & & & & & \\
\hline \multirow[t]{6}{*}{ Interpersonal } & INT1 & $.80^{*}$ & .37 & .64 & .90 & $14.83(9)$ & .096 & 1.65 & .024 & .97 & .94 & .99 & .065 & .61 \\
\hline & INT2 & $.78^{*}$ & .40 & .61 & & & & & & & & & & \\
\hline & INT3 & $.76^{*}$ & .42 & .58 & & & & & & & & & & \\
\hline & INT4 & $.79^{*}$ & .38 & .62 & & & & & & & & & & \\
\hline & INT5 & $.80^{*}$ & .37 & .64 & & & & & & & & & & \\
\hline & INT6 & $.78^{*}$ & .39 & .61 & & & & & & & & & & \\
\hline \multirow[t]{5}{*}{ Informational } & INF1 & $.78^{*}$ & .40 & .61 & .92 & $9.61(5)$ & .087 & 1.92 & .021 & .98 & .95 & .99 & .064 & .70 \\
\hline & INF2 & $.85^{*}$ & .28 & .72 & & & & & & & & & & \\
\hline & INF3 & $.86^{*}$ & .26 & .74 & & & & & & & & & & \\
\hline & INF4 & $.89^{*}$ & .22 & .79 & & & & & & & & & & \\
\hline & INF5 & $.81^{*}$ & .34 & .66 & & & & & & & & & & \\
\hline
\end{tabular}

Note: $* \mathrm{p}<.001$

FL: factor loading; ER: error; IR: individual reliability; CR: composite reliability.

\subsubsection{Reliability}

Table 3 presents the final set of items and scale reliabilities. We evaluated the reliability for each service fairness dimension by measuring internal consistency, including individual item reliability and composite reliability.

The lowest value of individual item reliability is .52 . Thus, all items satisfy the requirement of minimum .5 for individual item reliability (Hair, Anderson, Tatham, \& Black, 1998). In addition, composite reliabilities for all service fairness dimensions exceed .87 which meets the preferred level of .6 (Fornell \& Larcker, 1981).

\subsubsection{Validity}

\subsubsection{Criterion Validity}

According to prior empirical studies there is a significant and positive relationship between fairness and customer satisfaction (Szymanski \& Henard, 2001; Tax, Brown, \& Chandrashekaran, 1998). Therefore, we used customer satisfaction as the criterion variable. We assessed the level of satisfaction using three items based on the following semantic differential scale: $1=$ very dissatisfied, $7=$ very satisfied; $1=$ very terrible, $7=$ very perfect; $1=$ very angry, $7=$ very happy. Table 4 reports the results of the Pearson correlation analysis test of the criterion validity for each service fairness dimension. The results show that all five fairness dimensions significantly and positively relate with customer satisfaction $(\mathrm{p}<.001)$. This supports criterion validity.

\subsubsection{Convergent Validity}

We individually tested the unidimensionality and convergent validity of the five dimensions of service fairness by CFA. Table 3 shows the results.

First, we used model fitness to evaluate the unidimensionality. The results of the individual evaluations for five dimensions show hat five measurement models' chi-square value is non-significant, chi-square value divided by degree of freedom is less than 3 (Carmines \& McIver, 1981), RMR(root mean squared residual) is less than .05 
(Byrne, 2001), GFI (goodness of fit index) is greater than .90 (Hu \& Bentler, 1999), AGFI (adjusted goodness of fit index) is greater than .90 (Hu \& Bentler, 1999), CFI (comparative fit index) is greater than .95 (Hu \& Bentler, 1999), RMSEA (root mean squared error of approximation) is less than 0.08 (Browne \& Cudeck, 1992). Therefore, each of the five dimensions of service fairness we propose has unidimensionality.

To assess convergent validity, we measured the average variance extracted (AVE) for all of the service fairness dimensions. It is recommended that the AVE should be greater than .5 (Fornell \& Larcker, 1981) meaning that $50 \%$ above variance of the indicators is accounted for. All AVE values (Table 3) are greater than .5 thus indicating convergent validity. We examined the significance and direction of the factor loadings to further confirm convergent validity of the indicators for each service fairness dimension (Anderson \& Gerbing, 1988). All $t$ values are highly significant $(\mathrm{p}<.001)$ and in the anticipated direction. Therefore, we can conclude that convergent validity exists for five service fairness dimensions.

Table 4. Correlation coefficients and square root of variance extracted $(\mathrm{N}=200)$

\begin{tabular}{|c|c|c|c|c|c|c|c|c|}
\hline & mean & std dev & outcome & price & procedural & interpersonal & informational & satisfaction \\
\hline outcome & 5.30 & 0.78 & $.84^{\mathrm{a}}$ & & & & & \\
\hline price & 4.58 & 1.02 & $.58 *$ & $.79^{\mathrm{a}}$ & & & & \\
\hline procedural & 5.15 & 0.82 & $.42 *$ & $.50 *$ & $.75^{\mathrm{a}}$ & & & \\
\hline interpersonal & 5.39 & 0.82 & $.37 *$ & $.41 *$ & $.35^{*}$ & $.78^{\mathrm{a}}$ & & \\
\hline informational & 5.35 & 0.93 & $.41^{*}$ & $.50 *$ & $.45^{*}$ & $.56^{*}$ & $.84^{\mathrm{a}}$ & \\
\hline satisfaction & 5.19 & 0.96 & $.30 *$ & $.40^{*}$ & $.42 *$ & $.38^{*}$ & $.52 *$ & $.91^{\mathrm{a}}$ \\
\hline
\end{tabular}

Note: $* \mathrm{p}<0.001$.

${ }^{\mathrm{a}}$ represents square root of average variance extracted.

\subsubsection{Discriminant Validity}

Our exploratory factor analysis has provided a significant evidence for discriminant validity of service fairness dimensions. Another measure of discriminant validity is to evaluate whether the square roots of the AVE of two dimensions are greater than the correlation between them (Fornell \& Larcker, 1981). Table 4 indicates that this condition is satisfied for all dimensions; all values on the diagonal are significantly greater than those off the diagonal. As a final step to confirm discriminant validity we compared two nested models for each pair of service fairness dimensions in which we either allowed the correlation between two dimensions to be free or restricted to 1 . Our empirical result supports discriminant validity because the chi-square statistic is significantly lower in the unconstrained model than in the constrained model for all dimensions $(\mathrm{p}<.05)$. Therefore, the existence of discriminant validity for five service fairness dimensions is supported.

Overall this reveals our five service fairness dimensions are reliable and valid. Our next step was to examine structural relationships between these dimensions.

\section{The Factor Structure of Service Fairness}

To clarify the structural relationship we tested the underlying factor structure of the 26 items by comparing competing models using CFA. We followed Noar's (2003) suggestion to analyze possible competing models; each with a distinct factor structure. Figure 1 shows the six competing models and a description of each model follows.

one-order one-factor model

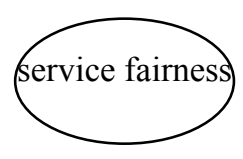

two-order two-factor model

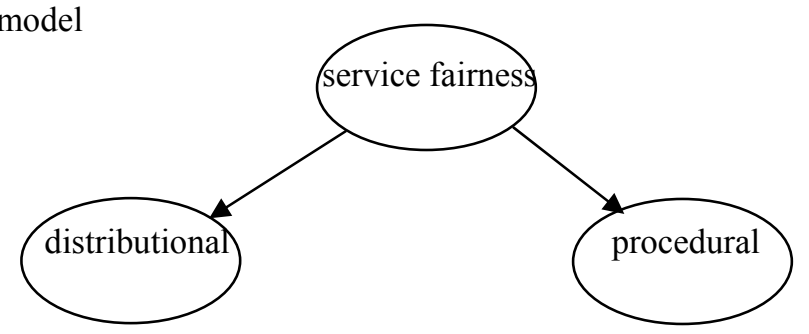


Two-order three-factor model

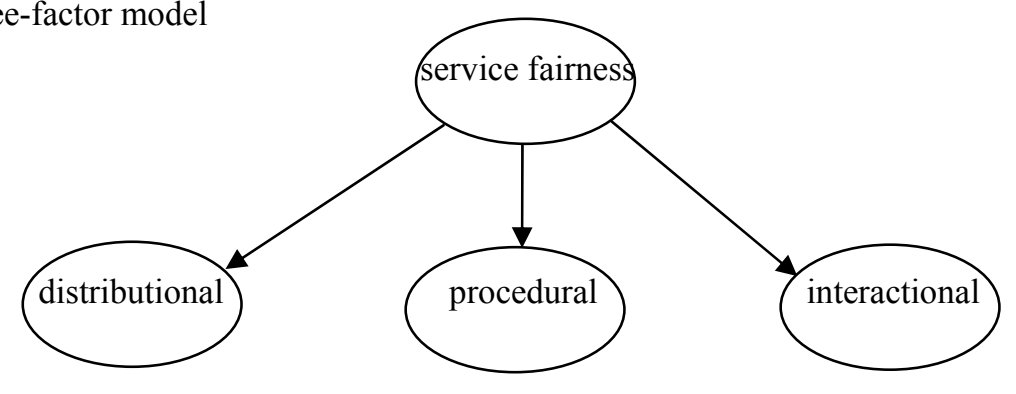

Two-order five-factor model

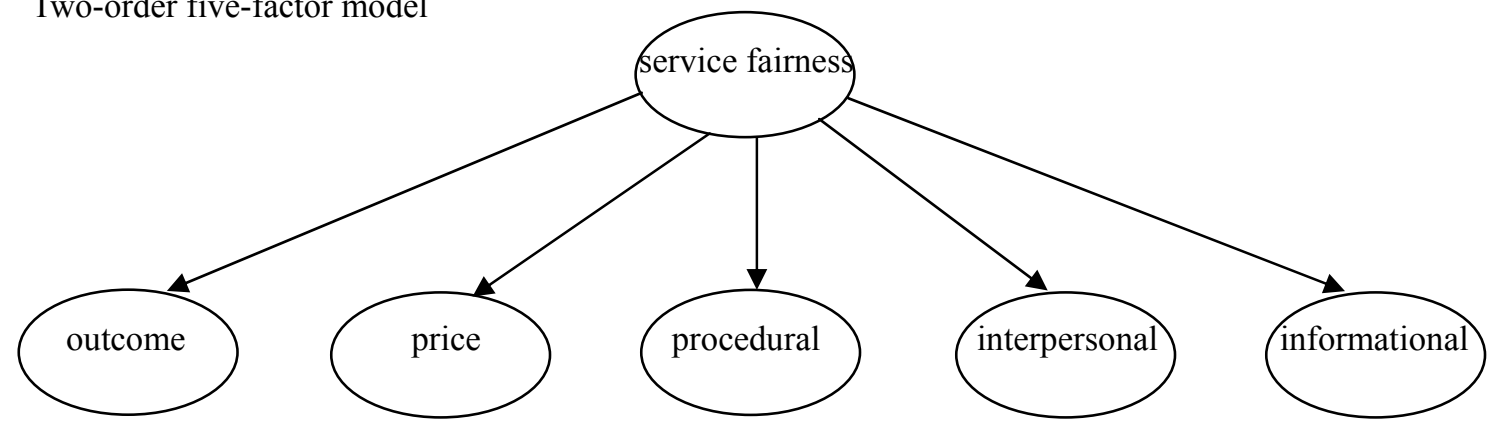

Three-order model

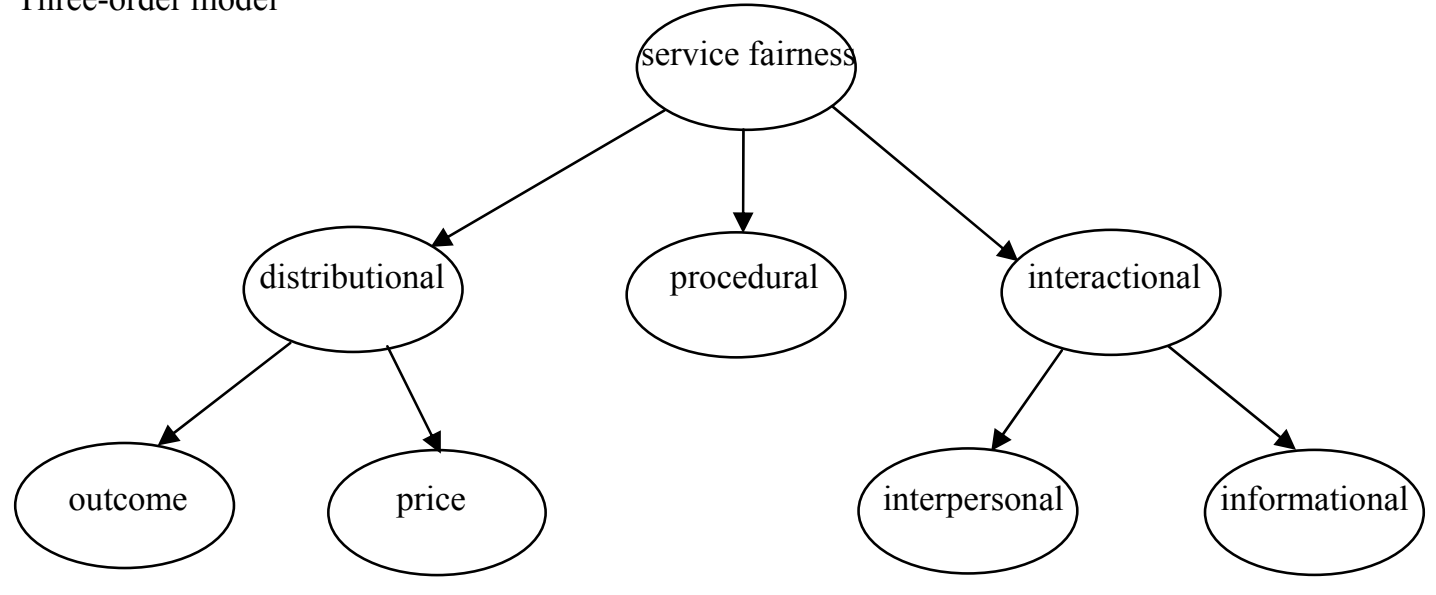

One-order five-factor correlation model

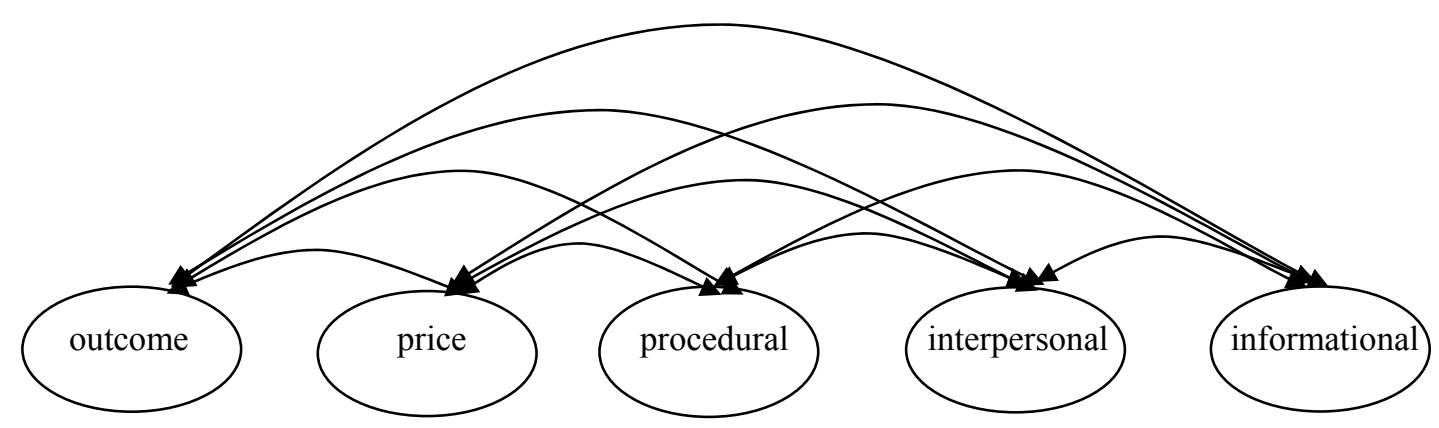

Figure 1. Six competing models of service fairness 
Based on Ambrose's (2001) and Lind's (2001) argument, we designed a one-order one-factor model of service fairness. In this case, all items from the five subscales (outcome, price, procedural, interpersonal, and informational) were used to measure a single factor model (service fairness).

On the other hand, some literature on fairness and justice (e.g, Brockner \& Wiesenfeld, 1996) led to a conceptual two factor model based on distributional fairness and procedural fairness. Our two-order two-factor model aggregated outcome and price items as distributional fairness, and procedural, interpersonal, and informational items to represent procedural fairness.

Some researchers also suggested fairness has three dimensions of distributional, procedural, and interactional fairness (e.g., Bies \& Moag, 1986; Cropanzano, Byre, Bobocel, \& Rupp, 2001). Our two-order three-factor model followed this point. This left the procedural fairness items unchanged (i.e., as above), aggregated outcome and price items to measure distributional fairness and incorporated interpersonal and informational items to measure interactional fairness.

We further divided distributional fairness into outcome fairness and price fairness and interactional fairness into interpersonal fairness and informational fairness. Then, we developed a one-order five-factor correlation model of outcome, price, procedural, interpersonal and informational fairness and also developed a two-order five-factor model.

Finally, we also developed a three-order model in which service fairness is composed of distributional, procedural, and interactional fairness. Following, distributional fairness is composed of outcome and price fairness as well as interactional fairness is composed of interpersonal and informational fairness.

We compared the fit of these competing models to identify the most representative structure. Table 5 summarizes the results of this analysis. The fit of the one-order one-factor model, two-order two-factor model, and two-order three-factor model is mediocre. The fit statistics of the two-order five-factor model, three-order model, and one-order five-factor correlation model are good. However, on further comparison we find the three-order model is a superior fit to the data $\left(\mathrm{x}^{2}(\mathrm{df}=292)=400.54, \mathrm{p}<.00, \mathrm{x}^{2} / \mathrm{df}=1.37, \mathrm{RMR}=.048, \mathrm{GFI}=.92, \mathrm{AGFI}=.90\right.$, $\mathrm{CFI}=.99$, RMSEA $=.042$, and $\mathrm{AIC}=520.54)$.

Table 5. CFA of structural model of service fairness

\begin{tabular}{lccccccccc}
\hline & $\mathrm{x}^{2}(\mathrm{df})$ & $\mathrm{p}$ & $\mathrm{x}^{2} / \mathrm{df}$ & $\mathrm{RMR}$ & $\mathrm{GFI}$ & AGFI & CFI & RMSEA & AIC \\
\hline one-order one-factor model & $2522.81(299)$ & .00 & 8.44 & .13 & .51 & .42 & .86 & .19 & 2626.81 \\
two-order two-factor model & $2460.09(297)$ & .00 & 8.28 & .18 & .51 & .42 & .88 & .19 & 2568.09 \\
two-order three-factor model & $2108.30(296)$ & .00 & 7.12 & .17 & .55 & .47 & .90 & .18 & 2218.30 \\
two-order five-factor model & $422.09(294)$ & .00 & 1.44 & .056 & .85 & .82 & .99 & .047 & 536.09 \\
one-order five-factor correlation model & $406.99(289)$ & .00 & 1.41 & .050 & .86 & .83 & .99 & .045 & 530.99 \\
three-order model & $400.54(292)$ & .00 & 1.37 & .048 & .92 & .90 & .99 & .042 & 520.54 \\
fit criterion & small & $>.05$ & $<3$ & $<.05$ & $>.90$ & $>.90$ & $>.95$ & $<.08$ & small \\
\hline
\end{tabular}

\section{Cross Validity of the Factor Structure of Service Fairness}

In order to consider the three-order model's stability we conducted an examination of cross-validity. This involved testing our proposed factor structure against a new respondent sample $(\mathrm{n}=178)$. The model fit is $\operatorname{good}\left(\mathrm{x}^{2} / \mathrm{df}=1.37, \mathrm{RMR}=.045, \mathrm{GFI}=.93, \mathrm{AGFI}=.91, \mathrm{CFI}=.99, \mathrm{RMSEA}=.040\right)$. This provides further confirmation that our three-order model of service fairness is stable.

\section{Conclusions}

Scholars and practitioners recognize the importance of maintaining relationships with customers. Service fairness is a means of retaining customers (e.g., Vargo \& Lusch, 2004). Despite the fact that many studies recognize the role of fairness there little academic research explicitly examines this construct in the consumer-retailer context. In particular researchers of service fairness rarely consider all components of service fairness and its factor structure.

This study confirms that service fairness as a multidimensional concept. It is plausible to conclude that consumers' overall judgment of service fairness depends on the five basic dimensions of outcome fairness, price fairness, procedural fairness, interpersonal fairness, and informational fairness. This involves the feeling that service consumers have been treated (un)equally as far as distribution of outcomes (outcome fairness) and the charge for service (price fairness). It covers the feeling that the procedures and processes performed by the 
service provider are handled in an even-handed way; not favoring any one group (procedural fairness). Fairness perceptions involve the manner of interpersonal interactions between the service provider and consumers (interpersonal fairness). Finally, fairness perceptions also involve consumers' perception about open, thorough, reasonable, and timely information provided by the service provider (informational fairness).

Without a clear and complete description of the dimensionality of service fairness, prior researchers could not define the factor structure of service fairness. This study reveals the multidimensional nature of service fairness and evolving understanding requires developing an appropriate understanding of relationships between these dimensions. This study also clarifies the relationship among the five dimensions of service fairness. This is an important contribution as the extant literature lacks this understanding. We find the structure of a three-order model is the best fit to the domain of service fairness. According to this model, service fairness is composed of distributional fairness, procedural fairness, and interactional fairness. Distributional fairness has two sub-dimensions of outcome fairness and price fairness while interactional fairness comprises interpersonal fairness and informational fairness.

Through a rigorous scale development process we developed five subscales to measure the components of consumer service fairness. Our each subscale of service fairness is a concise multiple-item scale with good reliability and validity. Using our scales to test consumers, service providers can understand their consumers' perceptions of service fairness, establish the improving priorities, and so facilitate improvements in service delivery. The instrument has been designed to be applicable across a broad spectrum of services and can be easily adapted to fit the characteristics or specific research needs of a particular industry. We hope the availability of this instrument will stimulate much-needed empirical research focusing on service fairness and its antecedents and consequences.

\section{Acknowledgement}

The author is grateful to National Science Council in Taiwan for the financial support (NSC 97-2410-H-024-006).

\section{References}

Anderson, J. C., \& Gerbing, D. W. (1988). Structural equation modeling in practice: A review and recommended $\begin{array}{lllll}\text { two-step approach. } & \text { Psychological }\end{array}$ http://dx.doi.org/10.1037//0033-2909.103.3.411

Ashworth, L., \& Free, C. (2006). Marketing dataveillance and digital privacy: Using theories of justice to understand consumers' online privacy concerns. Journal of Business Ethics, 67(2), 107-123. http://dx.doi.org/10.1007/s10551-006-9007-7

Beugre, C. D. (1998). Managing fairness in organizations. Westport, CT: Quorum.

Bies, R. J., \& Moag, J. S. (1986). Interactional justice: Communication criteria of fairness. In R. J. Lewicki, B. H. Sheppard, \& M. H. Bazerman (Eds.), Research on negotiation in organizations (pp. 43-55). Greenwich CT: JAI Press.

Blader, S. L., \& Tyler, T. R. (2003). What constitutes fairness in work settings? A four-component model of procedural justice. Human Resource Management Review, 13(1), 107-126. http://dx.doi.org/10.1016/S1053-4822(02)00101-8

Bowen, D. E., Gilliland, S. W., \& Folger, R. (1999). HRM and service fairness: How being fair with employees spills over to customers. Organizational Dynamics, 27(3), 7-23. http://dx.doi.org/10.1016/S0090-2616(99)90018-9

Brockner, J., \& Wiesenfeld, B. M. (1996). An integrative framework for explaining reactions to decisions: Interactive effects of outcomes and procedures. Psychological Bulletin, 120(2), 189-208. http://dx.doi.org/10.1037//0033-2909.120.2.189

Carr, C. L. (2007). The FAIRSERV model: Consumer reactions to services based on a multidimensional evaluation of service fairness. Decision Sciences, 38(1), 107-130. http://dx.doi.org/10.1111/j.1540-5915.2007.00150.x

Churchill, G. A. (1979). A paradigm for developing better measures of marketing constructs. Journal of Marketing Research, 16(1), 64-73. http://dx.doi.org/10.2307/3150876

Clemmer, E. C. (1993). An investigation into the relationship of fairness and customer satisfaction with services. In R. Cropanzano (Ed.), Justice in the workplace: Approaching fairness in human resource management (pp. 
193-207). Hillsdale, NJ: Lawrence Erlbaum.

Cohen, R. L. (1987). Distributive justice: Theory and research. Social Justice Research, 1(1), 19-40. http://dx.doi.org/10.1007/BF01049382

Colquitt, J. A. (2001). On the dimensionality of organizational justice: A construct validation of a measure. Journal of Applied Psychology, 86(3), 386-400. http://dx.doi.org/10.1037//0021-9010.86.3.386

Colquitt, J. A., Wesson, M. J., Porter, C. O. L. H., Conlon, D. E., \& Ng, K. Y. (2001). Justice at the millennium: A meta-analytic review of 25 years of organizational justice research. Journal of Applied Psychology, 86(3), 425-445. http://dx.doi.org/10.1037/0021-9010.86.3.425

Cropanzano, R., \& Ambrose, M. (2001). Procedural and distributive justice are more similar than you think: A monistic perspective and a research agenda. In J. Greenberg \& R. Cropanzano (Eds.), Advances in organizational justice (pp. 119-151). Stanford, CA: Stanford University Press.

Cropanzano, R., Byre, Z. S., Bobocel, D. R., \& Rupp, D. E. (2001). Self-enhancement biases, laboratory experiments, and the increasingly crowded world of organizational justice. Journal of Vocational Behavior, 58(2), 260-272. http://dx.doi.org/10.1006/jvbe.2001.1798

Darke, P. R., \& Dahl, D. W. (2003). Fairness and discounts: The subjective value of a bargain. Journal of Consumer Psychology, 13(3), 328-338. http://dx.doi.org/10.1207/S15327663JCP1303_13

Fornell, C., \& Larcker, D. F. (1981). Evaluating structural equation models with unobservable and measurement errors. Journal of Marketing Research, 18(1), 39-50. http://dx.doi.org/10.2307/3151312

Gerbing, D. W., \& Anderson, J. C. (1988). An updated paradigm for scale development incorporating unidimensionality and its assessment. Journal of Marketing Research, 25(2), 186-192. http://dx.doi.org/10.2307/3172650

Gilliland, S. W. (1993). Effects of procedural and distributive justice on reactions to a selection system. Journal of Applied Psychology, 79(5), 691-701. http://dx.doi.org/10.1037//0021-9010.79.5.691

Goodwin, C., \& Ross, I. (1992). Consumer responses to service failures: Influences of procedural and interactional fairness perceptions. Journal of Business Research, 25(2), 149-163. http://dx.doi.org/10.1016/0148-2963(92)90014-3

Greenberg, J. (1993). The social side of fairness: Interpersonal and informational classes of organizational justice. In R. Cropanzano (Ed.), Justice in the workplace: Approaching fairness in human resource management (pp. 79-103). Hillsdale, NJ: Erlbaum.

Greenberg, J. (1996). The quest for justice: Essays and experiments. Thousand Oaks, CA: Sage.

Hair, J. F. Jr., Anderson, R. E., Tatham, R. L., \& Black, W. C. (1998). Multivariate data analysis (5th ed.). New York: Macmillan.

Homans, G. (1961). Social behavior: Its elementary forms. New York: Harcourt Brace, and World.

Lacey, R., \& Sneath, J. Z. (2006). Customer loyalty programs: Are they fair to consumers? Journal of Consumer Marketing, 23(7), 458-464. http://dx.doi.org/10.1108/07363760610713000

Leventhal, G. S. (1980). What should be done with equity theory? New approaches to the study of fairness in social relationships. In K. J. Gergen, M. S. Greehberg, \& R. H. Willis (Eds.), Social exchange: Advances in theory and research (pp. 27-55). New York: Plenum Press.

Lind, E. A. (2001). Fairness heuristic theory: Justice judgments as pivotal cognitions in organizational relations. In J. Greenberg \& R. Cropanzano (Eds.), Advances in organization justice (pp. 56-88). CA: Stanford University Press.

Martins, M., \& Monroe, K. B. (1994). Perceived price fairness: A new look at an old construct. Advances in Consumer Research, 21(1), 75-78.

Maxham, J., \& Netemeyer, R. (2003). Firms reap what they sow: The effects of shared values and perceived organizational justice on customers' evaluations of complaint handling. Journal of Marketing, 67(1), 46-62. http://dx.doi.org/10.1509/jmkg.67.1.46.18591

Mayser, S., \& von Wangenheim, F. (2013). Perceived fairness of differential customer treatment: Consumers' understanding of distributive justice really matters. Journal of Service Research, 16(1), 99-113. http://dx.doi.org/10.1177/1094670512464274 
Nguyen, B., \& Klaus, P. (2013). Retail fairness: Exploring consumer perceptions of fairness towards retailers' marketing tactics. Journal of Retailing and Consumer Services, 20(3), 311-324. http://dx.doi.org/10.1016/j.jretconser.2013.02.001

Noar, S. M. (2003). The role of structural equation modeling in scale development. Structural Equation Modeling: A Multidisciplinary Journal, 10(4), 622-647. http://dx.doi.org/10.1207/S15328007SEM1004_8

Sindhav, B., Holland, J., Rodie, A. R., Adidam, P. T., \& Pol, L. G. (2006). The impact of perceived fairness on satisfaction: Are airport security measures fair? Does it matter? Journal of Marketing Theory and Practice, 14(4), 323-335. http://dx.doi.org/10.2753/MTP1069-6679140406

Szymanski, D. M., \& Henard, D. H. (2001). Customer satisfaction: A meta-analysis of the empirical evidence. Journal of the Academy of Marketing Science, 29(1), 16-35. http://dx.doi.org/10.1177/0092070301291002

Tax, S. S., Brown, S. W., \& Chandrashekaran, M. (1998). Customer evaluations of service complaint experiences: Implications for relationship marketing. Journal of Marketing, 62(2), 60-76. http://dx.doi.org/10.2307/1252161

Tyler, T. R., \& Bies, R. J. (1990). Beyond formal procedures: The interpersonal context of procedural justice. In J. S. Carroll (Ed.), Applied social psychology and organizational settings (pp. 77-98). Hillsdale, NJ: Erlbaum.

Vargo, S. L., \& Lusch, R. F. (2004). Evolving to a new dominant logic for marketing. Journal of Marketing, 68(1), 1-17. http://dx.doi.org/10.1509/jmkg.68.1.1.24036

Xia, L., Monroe, K. B., \& Cox, J. L. (2004). The price is unfair! A conceptual framework of price fairness perceptions. Journal of Marketing, 68(4), 1-15. http://dx.doi.org/10.1509/jmkg.68.4.1.42733

Yieh, K., Chiao, Y.-C., \& Chiu, Y.-K. (2007). Understanding the antecedents to customer loyalty by applying structural equation modeling. Total Quality Management and Business Excellence, 18(3), 267-284. http://dx.doi.org/10.1080/14783360601152400

\section{Copyrights}

Copyright for this article is retained by the author(s), with first publication rights granted to the journal.

This is an open-access article distributed under the terms and conditions of the Creative Commons Attribution license (http://creativecommons.org/licenses/by/3.0/). 